\title{
X Chromosome Dosage and the Response to Cerebral Ischemia
}

\author{
L. Christine Turtzo, ${ }^{1,2,3,4}$ Chad Siegel, ${ }^{1,2}$ and Louise D. McCullough ${ }^{1,2}$ \\ Departments of ${ }^{1}$ Neurology and ${ }^{2}$ Neuroscience, University of Connecticut Health Center, Farmington, Connecticut 06030 , ${ }^{3}$ Center for Neuroscience and \\ Regenerative Medicine, Henry M. Jackson Foundation, Rockville, Maryland 20852, and ${ }^{4}$ Laboratory of Diagnostic Radiology Research, Clinical Center, \\ National Institutes of Health, Bethesda, Maryland 20892
}

Gonadal hormones contribute to ischemic neuroprotection, but cannot fully explain the observed sexual dimorphism in stroke outcomes seen during life stages with low sex steroid hormones. Sex chromosomal complement (XX in females; XY in males) may also contribute to ischemic sexual dimorphism. A transient middle cerebral artery occlusion model was used to investigate the role of $\mathrm{X}$ chromosome dosage in female XX and XO littermates of two mouse strains ( $P a f$ and $E d a^{T a}$ ). Cohorts of XX and XO gonadally intact, ovariectomized, and ovariectomized females supplemented with estrogen were examined. Infarct sizes were equivalent between ovariectomized XX and XO mice, between intact XX and XO mice, and between estrogen-supplemented ovariectomized XX and XO mice. This is the first study to investigate the role of sex chromosome dosage in the response to cerebral ischemia. Neither the number of X chromosomes nor the parent of origin of the remaining X chromosome had a significant effect on the degree of cerebral infarction after experimental stroke in adult female mice. Estrogen was protective against cerebral ischemia in both XX and XO mice.

\section{Introduction}

Sex differences in both animal models of stroke and in clinical populations are increasingly recognized (for review, see Bushnell, 2008; Reeves et al., 2008; Turtzo and McCullough, 2010). The incidence of stroke in women increases at the time of menopause, but does not surpass that of men until after the age of 85 (LloydJones et al., 2009). The underlying etiology of this sexual dimorphism has been largely attributed to exposure to ovarian hormones, particularly estrogen (Herson et al., 2009). In rodent models, females have smaller infarcts than males when estrogen is present (Alkayed et al., 1998), an effect that is reversed with ovariectomy and restored with estrogen replacement (Alkayed et al., 2000). Estrogens are also neuroprotective in males (McCullough et al., 2001) and in middle-aged animals (Liu et al., 2009). However, clinical trials of postmenopausal estrogen replacement showed an increased ischemic stroke risk in treated women (Hulley et al., 1998; Viscoli et al., 2001; Wassertheil-Smoller et al., 2003). While sex steroids clearly have an effect on damage in cerebral ischemia, evidence is emerging that there are intrinsic sex differences independent of hormonal status (for review, see Turtzo and McCullough, 2010). Data from both cell culture of immature neurons (Du et al., 2004) and in vivo studies of neonatal animals (Renolleau et al., 2007, 2008) indicate that mecha-

\footnotetext{
Received Feb. 4, 2011; revised July 6, 2011; accepted July 21, 2011.

Author contributions: L.D.M. designed research; L.C.T. and C.S. performed research; L.C.T. contributed unpublished reagents/analytic tools; L.C.T., C.S., and L.D.M. analyzed data; L.C.T. and L.D.M. wrote the paper.

We thank the National Institutes of Health for funding support (L.D.M.: 1R01-NS055215 and 5F31-NS062608).

We also thank Matthew Siegel for technical assistance in the blinding of images for the infarct size analysis.

The authors declare no competing financial interests.

Correspondence should be addressed to Dr. Louise D. McCullough, Department of Neurology, University of Connecticut Health Center, 263 Farmington Avenue, MC1840, Farmington, CT 06030. E-mail: Imccullough@uchc.edu. DOI:10.1523/JNEUROSCI.0621-11.2011

Copyright $\odot 2011$ the authors $\quad 0270-6474 / 11 / 3113255-05 \$ 15.00 / 0$
}

nisms of cell death differ between males and females even in the absence of hormones (for review, see Lang and McCullough, 2008). Expression of both autosomal and sex chromosomelinked genes in the mouse brain displays regional sexual dimorphism, as well as sex-specific imprinting from the parent of origin (Gregg et al., 2010). In clinical studies, childhood ischemic stroke is more common in boys than in girls, both in preadolescents and adolescents, suggesting a greater influence of sex chromosomes than gonadal hormones in this population (Golomb et al., 2009), although exposure to testosterone could also be a factor.

To date, no experimental studies have investigated the contribution of sex chromosome complement to outcomes after cerebral ischemia. The hypothesis that the dosage of X chromosomes influences the response to cerebral ischemia was tested, with females predicted to have an advantage over males secondary to their additional $\mathrm{X}$ chromosome. To address this, ischemic sensitivity was examined in two strains of mice where a proportion of females lack the second X chromosome.

\section{Materials and Methods}

Experimental animals. The present study was conducted in accordance with the NIH guidelines for the care and use of animals in research and under protocols approved by the Animal Care and Use Committee of the University of Connecticut Health Center. Paf/Y males and Paf/+ females were originally purchased from the Jackson Laboratory to establish a breeding colony, from which Paf/+ (XX), Paf/Paf (XX), and Paf/O (XO) females and $P a f / Y(X Y)$ and wild-type (XY) males were generated and distinguished by coat phenotype (Lane and Davisson, 1990). The Paf mutation is associated with an $\mathrm{X}$ chromosome inversion spanning the pseudoautosomal region boundary (Burgoyne and Evans, 2000). As a result of this inversion, Paf males have an increased frequency of meiotic nondisjunction, resulting in high levels of sperm with abnormal numbers of sex chromosomes, and father $39 \mathrm{XO}$ female progeny at a frequency as high as 20\% (Raefski and O'Neill, 2005). Hemizygous females (Paf/O; 
$\mathrm{XO})$ can be identified by their distinctive patchy hair loss, while their heterozygous female (Paf/+; XX) littermates have striped fur patterns (Lane and Davisson, 1990). Aside from coat pattern differences, these Paf $\mathrm{XO}$ females have no described abnormalities, and are fertile.

$E d a^{T a} /+(\mathrm{XX})$ and $E d a^{T a} /+\mathrm{O}(\mathrm{XO})$ female mice were purchased from the Jackson Laboratory(Probst et al., 2008). The $E d a^{T a}$ XO mouse, which was originally described as the X-linked tabby (Ta) mutation (Falconer, 1952), results from a $2 \mathrm{~kb}$ deletion at the $5^{\prime}$ end of the ectodysplasin A (Eda) gene (Ferguson et al., 1997; Srivastava et al., 1997). In contrast to $\mathrm{Paf} \mathrm{XO}$ mice, $E d a^{T a} \mathrm{XO}$ mice exhibit growth retardation, high-frequency hearing loss, reduced thyroid activity, reduced body temperature, and some behavioral abnormalities (Grüneberg, 1965, 1971a,b). Hemizygous $\mathrm{XO}\left(E d a^{T a} / \mathrm{O}\right)$ females can be distinguished from their XX littermates on the basis of coat color patterns, and are fertile (Probst et al., 2008). Crosses of $E d a^{T a} / \mathrm{O}$ females to $E d a^{T a} / \mathrm{Y}$ males yield a frequency of $E d a^{T a}$ XO offspring from 10 to 20\% (Probst et al., 2008).

Bone marrow preparation and fluorescence in situ hybridization. Bone marrow was extracted when the mice were killed from femurs and tibiae of representative XO, XX, and XY mice per the The Jackson Laboratory's protocol (http://www.jax.org/cyto/marrow_preps_alt.html). Mouse X and $\mathrm{Y}$ chromosome-specific probes were obtained from STARFISH (Cambio), and fluorescence in situ hybridization (FISH) was performed on bone marrow spreads as previously described (Probst et al., 2008).

Ovariectomy and hormonal manipulation. Ovaries were surgically removed $14 \mathrm{~d}$ before $\mathrm{MCAO}$ and mice were implanted with a subcutaneous SILASTIC capsule $(0.062$ inch inner diameter; 0.125 inch outer diameter) filled with either $0.035 \mathrm{ml}$ of $17 \beta$-estradiol ( $180 \mu \mathrm{g} / \mathrm{ml}$; Sigma $)$ in sesame oil or oil vehicle as described previously (McCullough et al., 2005). Uterine weights were recorded when the mice were killed to confirm loss of estrogenic effects, and serum $17 \beta$-estradiol (E2) was measured by ELISA (IBL Hamburg).

Ischemic model. Cerebral ischemia was induced by either 60 or $90 \mathrm{~min}$ of reversible middle cerebral artery occlusion (MCAO, 20-25 g mice 10-12 weeks of age) under isoflurane anesthesia, followed by reperfusion, as previously described (McCullough et al., 2005). A midline ventral neck incision was made, and unilateral MCAO was performed by inserting a 6.0 Doccol monofilament into the right internal carotid artery 6 $\mathrm{mm}$ from the internal carotid/pterygopalatine artery bifurcation via an external carotid artery stump. Sham-operated animals underwent the same surgical procedure, but the suture was not advanced into the internal carotid artery. Rectal muscle temperatures were maintained between 36.5 and $37.5^{\circ} \mathrm{C}$ during surgery and ischemia with an automated temperature control feedback system. In a separate nonsurvival cohort of animals, laser Doppler flow, arterial blood gases, and mean arterial pressure were monitored to ensure consistency of occlusion and equivalency of physiological variables between groups.

Behavioral scoring. Neurological deficits were scored $1 \mathrm{~h}$ after initiation of MCAO and when the mice were killed at 24 or $72 \mathrm{~h}$ after stroke. The scoring system was as follows: 0 , no deficit; 1 , forelimb weakness and torso turning to the affected side when held by tail; 2, circling to affected side; 3 , unable to bear weight on affected side; and 4 , no spontaneous locomotor activity or barrel rolling (Li et al., 2004).

Histological assessment. Mice were killed at either 24 or $72 \mathrm{~h}$ after the onset of MCAO for infarct volume analysis. Brains were sectioned into five $2 \mathrm{~mm}$ slices, then stained with 2,3,5-triphenyltetrazolium chloride for $8 \mathrm{~min}$ at $37^{\circ} \mathrm{C}$, followed by fixation in $4 \%$ paraformaldehyde. After digitalization of images, infarct volume was assessed using SigmaScan Pro (SPSS) as previously described (McCullough et al., 2005).

Statistical analysis. Data from individual experiments are presented as mean \pm SEM. One-way ANOVA (with Tukey post hoc correction, when appropriate) was used for the comparison of the mean infarct volume between the experimental groups. Nonparametric results were analyzed with the Mann-Whitney $U$ test. $p<0.05$ was considered statistically significant. Due to the differences in coat phenotype among the mice investigators were blinded to genotype after removal of the brain for infarct analysis. Power analysis was performed on all groups to confirm appropriateness of sample size ( $G$ power).

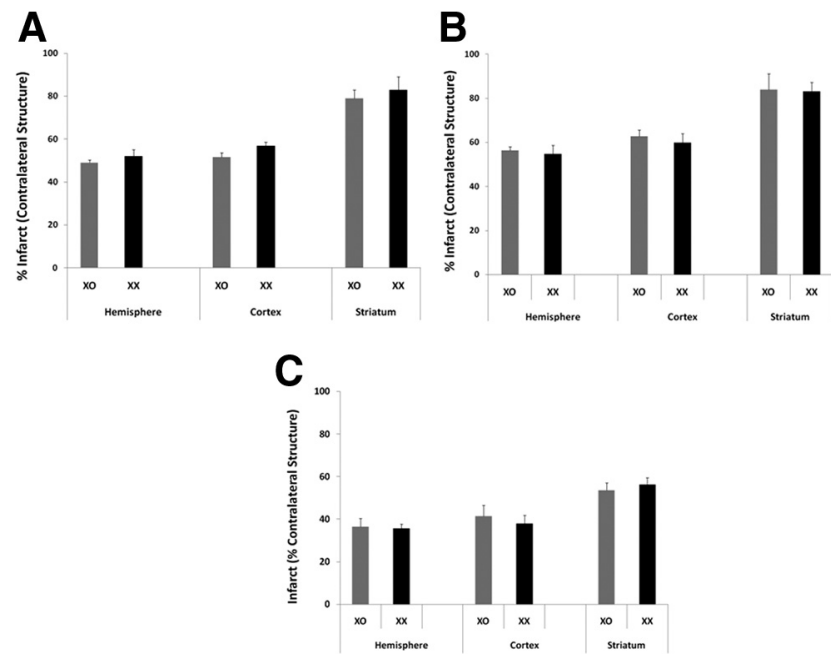

Figure 1. A, After a 90 min occlusion, infarct sizes at $24 \mathrm{~h}$ after stroke are similar between ovariectomized Paf XX and X0 females ( $n=8$ per genotype, respectively). $\boldsymbol{B}$, After 60 min of occlusion, at $72 \mathrm{~h}$ after stroke survival, there are no differences in infarct size between ovariectomized Paf XX and X0 females ( $n=7$ per genotype, respectively). $\boldsymbol{C}$, $X$ chromosome monosomy versus disomy has no effect on infarct size in estrogensupplemented ovariectomized Paf XX and X0 females ( $n=7$ per genotype, respectively) at $24 \mathrm{~h}$ after a 90 min occlusion.

\section{Results}

The ischemic sensitivity of Paf XO mice, which have loss of the paternally derived X chromosome, and their Paf XX littermates was compared. To confirm our coat phenotyping, we verified the $\mathrm{X}$ chromosome dosage in representative Paf XO and Paf XX females by sex chromosome-specific FISH. Baseline physiological parameters were similar between XO and XX females (data not shown). To eliminate the activational effects of ovarian hormones, a cohort of Paf XO and Paf XX littermates were ovariectomized $14 \mathrm{~d}$ before MCAO. With $90 \mathrm{~min}$ of ischemia, no differences were found in infarct size at $24 \mathrm{~h}$ after stroke between ovariectomized $P a f X O$ and $P a f X X$ females (hemisphere: $51 \%$ vs $49 \%$; SEM $\pm 4 \%$ vs $\pm 3 \% ; n=8, p>0.05$ ) (Fig. $1 A$ ). To confirm that a ceiling effect had not been reached, and that differences would not emerge in infarct size with longer-term survival, we performed additional studies with a less severe ischemic insult (60 min) and a $72 \mathrm{~h}$ survival. Again no differences were observed between Paf XO and Paf XX ovariectomized females (hemisphere: $55 \%$ vs $57 \%$; SEM \pm 1 vs $\pm 4 ; n=7, p>0.05$ ) after $72 \mathrm{~h}$ of ischemia (Fig. $1 B$ ). To confirm that Paf XO and Paf XX females were responsive to estrogen, a separate cohort of mice was supplemented with estrogen and subjected to a 90 min stroke with $24 \mathrm{~h}$ survival. As expected, estrogen levels were increased in supplemented animals $(\mathrm{PafXO}$ Ovx $+\mathrm{E} 2$ estrogen levels $=41.6 \pm 4$ $\mathrm{pg} / \mathrm{ml}$; Paf XX Ovx +E2 estrogen levels $=37.3 \pm 2 \mathrm{pg} / \mathrm{ml} ; p>$ 0.05). Infarct size was not significantly different between $P a f X O$ and $P$ afXX (hemisphere: $35 \%$ vs $36 \%$; SEM $\pm 4 \%$ vs $\pm 4 \%$; $n=7$, $p>0.05$, Fig. $1 C$ ), and was similar to gonadally intact $P a f X O$ and Paf XX mice and significantly smaller than ovariectomized $P a f$ $\mathrm{XO}$ and PafXX females (as seen in Fig. 1A). As predicted, ovariectomized females of both groups had very low estrogen levels $($ Ovx XX estrogen $=9 \pm 2 \mathrm{pg} / \mathrm{ml}$; Ovx XO estrogen $=6 \pm 2$ $\mathrm{pg} / \mathrm{ml} ; p>0.05)$ and atrophic uteri [Fig. $2 A$; Ovx XX uterine weight $(\mathrm{UW})=1.6 \pm 0 \mathrm{mg} / \mathrm{g}$ of body weight $(\mathrm{BW})$; Ovx XO $\mathrm{UW}=1.7 \pm 0.4 \mathrm{mg} / \mathrm{g}$ of BW; $p>0.05]$. Neurobehavioral deficits were identical between all ovariectomized XX and XO cohorts, both during ischemia and at $24 \mathrm{~h}$ (Fig. 2 B). 
A

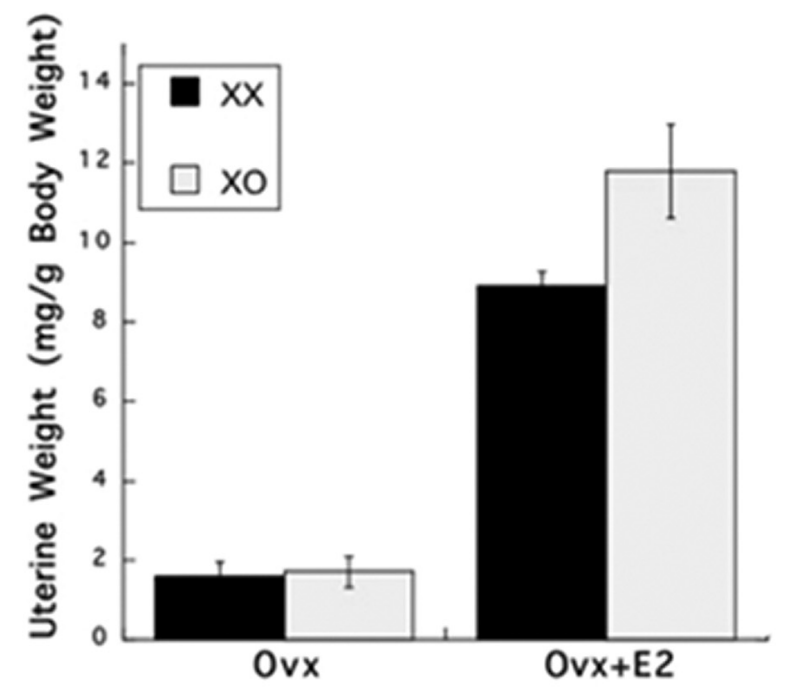

B

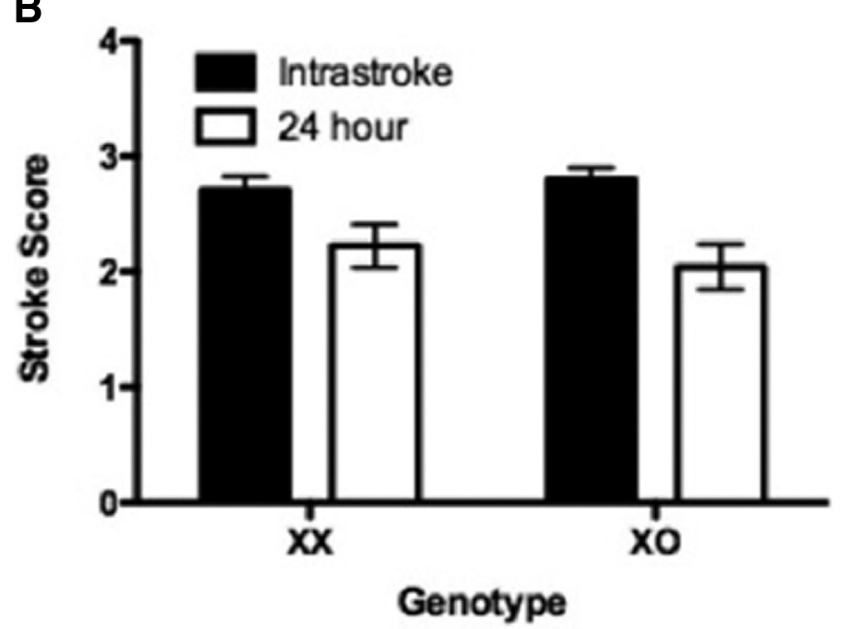

Figure 2. $X X$ and $X 0$ mice display similar responses to hormone loss via ovariectomy and in the neurobehavioral deficits induced by stroke. $A$, Uterine weights in XX and XO mice, expressed in milligrams of uterine weight per gram of body weight. Uterine atrophy occurs to a similar extent in ovariectomized $X X$ and $X 0$ mice. The effects of uterine atrophy are reversed by estrogen supplementation in ovariectomized XX and XO mice. $\boldsymbol{B}$, Neurobehavioral scores are similar between $X X$ and $X 0$ mice after 90 min of ischemia during both intraischemic and $24 \mathrm{~h}$ time points $(X X$ : intrastroke $=2.7 \pm 0.1 ; 24 \mathrm{~h}=2.2 \pm 00.2 ; X 0$ : intrastroke $=2.8 \pm 0.1 ; 24 \mathrm{~h}=$ $2.0 \pm 0.2 ; p>0.05)$.

We then examined gonadally intact $P a f X O$ and $P a f X X$ female littermates at $24 \mathrm{~h}$ after a $90 \mathrm{~min}$ cerebral occlusion to determine whether endogenous ovarian hormones (including progesterone, which is also lost with ovariectomy) interact with chromosome complement to influence ischemic outcome. No differences in ischemic sensitivity were observed in gonadally intact $\mathrm{Paf} X \mathrm{XO}$ and Paf XX female littermates at $24 \mathrm{~h}$ after a 90 min cerebral occlusion. There were no significant differences in infarct size between Paf XO and Paf XX intact females (hemisphere: $41 \%$ vs $45 \%$; SEM $\pm 6 \%$ vs $\pm 6 \% ; n=9, p>0.05$ ) (Fig. 3). Infarct size was slightly higher in gonadally intact females than in ovariectomized females supplemented with estrogen. This was not statistically significant and was seen in both XO and XX mice, and likely represents the fluctuations in infarct size seen throughout normal estrous (Carswell et al., 2000).

To reduce the likelihood that there were mutation-specific or imprinting effects confounding interpretation of X chromosome

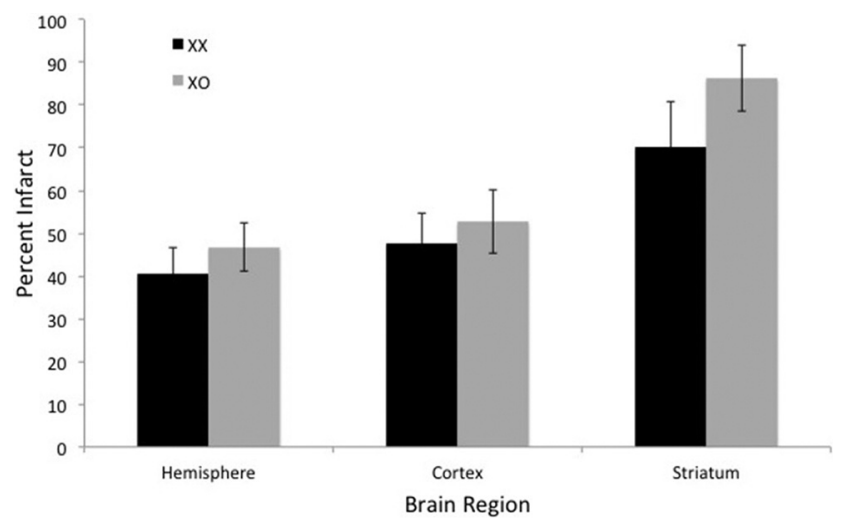

Figure 3. Infarct sizes are similar at $24 \mathrm{~h}$ after a 90 min occlusion in Paf $X X$ and $X 0$ female mice with intact ovaries and normally cycling sex steroid hormones ( $n=9$ per genotype).

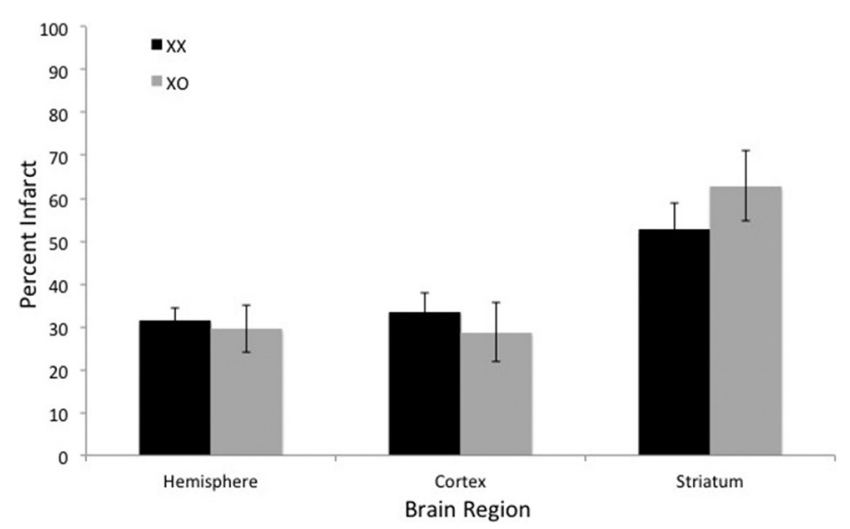

Figure 4. X chromosome monosomy versus disomy has no effect on infarct size in estrogensupplemented ovariectomized Eda ${ }^{\text {Ta }} X X$ versus Eda ${ }^{\text {Ta }} \mathrm{X}$ O females at $24 \mathrm{~h}$ after a 90 min occlusion ( $n=9$ per genotype). The smaller infarct sizes seen in the estrogen-supplemented group demonstrates that both $\mathrm{XX}$ and $\mathrm{XO}$ ovariectomized females are responsive to the neuroprotective effects of estrogen.

dosage, a second strain of XO mice $\left(E d a^{T a} / \mathrm{O}\right)$, which have loss of the maternally derived $\mathrm{X}$ chromosome, was examined. To control for hormonal variations in infarct size $E d a^{T a} / \mathrm{O}$ and $E d a^{T a} /+$ females were ovariectomized and supplemented with estrogen. This also allowed us to compare infarct size of $E d a^{T a} / \mathrm{O}$ with estrogen-treated Paf mice. There were no significant differences in infarct size at $24 \mathrm{~h}$ in $E d a^{T a} \mathrm{XO}$ versus XX females (hemisphere: $31 \%$ vs $29 \%$; SEM $\pm 3 \%$ vs $\pm 6 \% ; n=9 ; p>0.05$ ) (Fig. 4 ); estrogen levels $(\mathrm{Ovx}+\mathrm{E} 2 \mathrm{XX}$ estrogen levels $=28 \pm 2 \mathrm{pg} / \mathrm{ml}$; $\mathrm{Ovx}+\mathrm{E} 2 \mathrm{XO}$ estrogen levels $=33 \pm 2 \mathrm{pg} / \mathrm{ml} ; p>0.05)$ and uterine weights were similar between groups (Fig. 2; Ovx +E2 XX $\mathrm{UW}=8.9 \pm 0.7 \mathrm{mg} / \mathrm{g}$ of BW; Ovx $+\mathrm{E} 2 \mathrm{XO} \mathrm{UW}=11 \pm 1 \mathrm{mg} / \mathrm{g}$ of BW; $p<0.05)$. Infarct size was smaller in intact and in estrogen-treated mice than in ovariectomized mice, demonstrating that $\mathrm{XO}$ mice are responsive to estrogen.

\section{Discussion}

This is the first preclinical study to investigate the role of sex chromosome dosage in the response to stroke. No statistically significant differences in infarct size at 24 or $72 \mathrm{~h}$ after stroke were seen between two different strains of XO and XX mice, and this was independent of ovarian hormone status and the duration of ischemia. A strength of the present study is that two strains of $\mathrm{XO}$ mice with $\mathrm{X}$ chromosomes originating from different parent of origin were investigated. This allows preliminary investigation of the effects of X chromosome imprinting in stroke. The null chro- 
mosome originates from the father in the Paf XO, resulting in an $\mathrm{X}$ chromosome of maternal origin (Lane and Davisson, 1990). In the $E d a^{T a}$ XO mouse, the colony breeding strategy ensures that the normal X chromosome is paternal (Probst et al., 2008). No difference in infarct size in comparison to XX littermates was seen in gonadally intact $\mathrm{XO}$ mice with an $\mathrm{X}$ chromosome of either parent of origin, suggesting that $\mathrm{X}$ chromosome imprinting effects are either not present or below the limits of detection of the present study.

While this investigation showed no overall effect of X chromosome dosage or parental imprinting on the response to cerebral ischemia in this model, these results do not preclude the possibility that individual X-linked genes are important in the ischemic response in humans. While one of the $\mathrm{X}$ chromosomes in females is randomly inactivated during early development, up to $20 \%$ of X-linked genes escape X inactivation in humans (Carrel et al., 1999). In contrast, a much smaller percentage of $X$-inactivation escapees exist in mouse (Tsuchiya and Willard, 2000; Disteche et al., 2002). In addition, homologs of some genes present on the human $X$ chromosome are located on autosomes in mouse (Carrel et al., 1999; Tsuchiya and Willard, 2000; Disteche et al., 2002). For these genes, escape from $\mathrm{X}$ inactivation may be crucial for dosage in humans, but irrelevant in mouse. In addition, which genes escape from $\mathrm{X}$ inactivation can vary in a tissue-specific manner (Lopes et al., 2010). Whether a stressor, such as cerebral ischemia, can trigger expression of $\mathrm{X}$-inactivation escapees in humans or in mice has yet to be investigated.

There are several limitations to these studies. These results contrast with clinical studies of human X chromosome monosomy, in which women with Turner syndrome experience an almost threefold higher risk of cerebrovascular diseases than in XX women (Gravholt et al., 1998; Gravholt, 2005; Stochholm et al., 2006; Schoemaker et al., 2008). Although the XO mice studied here represent murine $\mathrm{X}$ chromosome monosomy, they are an imperfect model of human Turner syndrome. In contrast to XO women, who experience premature ovarian failure if not given supplemental hormones (Gravholt, 2001), Paf and $E d a^{T a}$ XO mice are fertile. This difference in ovarian function may explain the divergent outcomes in stroke sensitivity.

A relatively severe insult, with $90 \mathrm{~min}$ of ischemia followed by reperfusion, was initially used, which may have led to a ceiling effect, in which maximal damage has occurred, making it difficult to observe more subtle effects from X chromosome loss. To address this limitation, and to confirm that the infarct size remained equivalent between the XO and XX mice after a longer survival, the effect of a milder insult of $60 \mathrm{~min}$ of ischemia with $72 \mathrm{~h}$ survival was investigated. No significant differences were observed between XX and XO mice after the milder injury, either. As XO and XX females show no differences in lesion volume after mild or severe ischemia, the contribution of X chromosome dosage to the early effects of cerebral ischemia in mice is likely to be minimal. Importantly, only young adult mice were examined in this study, and thus the current investigation does not exclude the possibility that changes could occur with age, especially as $\mathrm{X}$ inactivation can become unstable with aging (Hatakeyama et al., 2004; Smrt et al., 2011).

In these studies, mice were ovariectomized as adults to eliminate the activational effects of ovarian hormones; however, mice had been exposed to ovarian hormones until the time of ovariectomy, which does not eliminate the organizational effects of ovarian hormones. The influence of X chromosome dosage on ischemic sensitivity is likely small and not easily seen in a system with long-standing exposure to the organizational effects of ste- roid hormones. Investigation of X chromosome loss in neonatal hypoxia-ischemia models may prove to be more informative, as mice of that age will not have experienced the surge of ovarian hormones at reproductive maturity. Likewise, studies in which mice are gonadectomized before puberty, then subjected to experimental stroke as adults, may be a better system in which to reduce the long-term organizational effects of sex steroid hormones.

While this is the first investigation to consider the role of intrinsic sex chromosome dosage in the response to cerebral ischemia, the present study leaves much unexplored. A recent study reported sex-specific parent of origin imprinting effects in the mouse brain, observed for both autosomal genes and the X chromosome (Gregg et al., 2010). Differential expression of these imprinting effects was observed in various brain regions. Whether or not the $\mathrm{Y}$ chromosome itself confers any increase or decrease in ischemic sensitivity is unknown. The presence of at least one $\mathrm{X}$ chromosome is crucial for rodent and human viability (Migeon, 2007), making an investigation of males with a YO phenotype impossible. An alternative approach could investigate the effects of cerebral ischemia in the XXY mouse model of Klinefelter syndrome (Lue et al., 2001), in which one of the two X chromosomes is thought to be randomly inactivated as in females to achieve dosage compensation between the sexes (Tüttelmann and Gromoll, 2010). Use of the four core genotypes model, in which gonadal sex can be separate from genetic sex (Becker et al., 2005; Arnold, 2009; Arnold and Chen, 2009), may also be a useful tool in further exploration of the role of the sex chromosomes themselves in stroke sensitivity.

In conclusion, $\mathrm{X}$ chromosome monosomy versus disomy does not significantly affect the degree of infarction in female mice either kept gonadally intact or ovariectomized as young adults.

\section{References}

Alkayed NJ, Harukuni I, Kimes AS, London ED, Traystman RJ, Hurn PD (1998) Gender-linked brain injury in experimental stroke. Stroke 29: 159-165; discussion 166.

Alkayed NJ, Murphy SJ, Traystman RJ, Hurn PD, Miller VM (2000) Neuroprotective effects of female gonadal steroids in reproductively senescent female rats. Stroke 31:161-168.

Arnold AP (2009) Mouse models for evaluating sex chromosome effects that cause sex differences in non-gonadal tissues. J Neuroendocrinol 21:377-386.

Arnold AP, Chen X (2009) What does the "four core genotypes" mouse model tell us about sex differences in the brain and other tissues? Front Neuroendocrinol 30:1-9.

Becker JB, Arnold AP, Berkley KJ, Blaustein JD, Eckel LA, Hampson E, Herman JP, Marts S, Sadee W, Steiner M, Taylor J, Young E (2005) Strategies and methods for research on sex differences in brain and behavior. Endocrinology 146:1650-1673.

Burgoyne PS, Evans EP (2000) A high frequency of XO offspring from $\mathrm{X}(\mathrm{Paf}) \mathrm{Y}^{\star}$ male mice: evidence that the Paf mutation involves an inversion spanning the X PAR boundary. Cytogenet Cell Genet 91:57-61.

Bushnell CD (2008) Stroke and the female brain. Nat Clin Pract Neurol 4:22-33.

Carrel L, Cottle AA, Goglin KC, Willard HF (1999) A first-generation $\mathrm{X}$-inactivation profile of the human X chromosome. Proc Natl Acad Sci U S A 96:14440-14444.

Carswell HV, Dominiczak AF, Macrae IM (2000) Estrogen status affects sensitivity to focal cerebral ischemia in stroke-prone spontaneously hypertensive rats. Am J Physiol Heart Circ Physiol 278:H290-294.

Disteche CM, Filippova GN, Tsuchiya KD (2002) Escape from X inactivation. Cytogenet Genome Res 99:36-43.

Du L, Bayir H, Lai Y, Zhang X, Kochanek PM, Watkins SC, Graham SH, Clark RS (2004) Innate gender-based proclivity in response to cytotoxicity and programmed cell death pathway. J Biol Chem 279:38563-38570.

Falconer DS (1952) A totally sex-linked gene in the house mouse. Nature 169:664-665. 
Ferguson BM, Brockdorff N, Formstone E, Ngyuen T, Kronmiller JE, Zonana J (1997) Cloning of Tabby, the murine homolog of the human EDA gene: evidence for a membrane-associated protein with a short collagenous domain. Hum Mol Genet 6:1589-1594.

Golomb MR, Fullerton HJ, Nowak-Gottl U, Deveber G (2009) Male predominance in childhood ischemic stroke: findings from the international pediatric stroke study. Stroke 40:52-57.

Gravholt CH (2001) Medical problems of adult Turner's syndrome. Horm Res 56 [Suppl 1]:44-50.

Gravholt CH (2005) Turner syndrome in adulthood. Horm Res 64 [Suppl 2]:86-93.

Gravholt CH, Juul S, Naeraa RW, Hansen J (1998) Morbidity in Turner syndrome. J Clin Epidemiol 51:147-158.

Gregg C, Zhang J, Butler JE, Haig D, Dulac C (2010) Sex-specific parent-oforigin allelic expression in the mouse brain. Science 329:682-685.

Grüneberg H (1965) Genes and genotypes affecting the teeth of the mouse. J Embryol Exp Morphol 14:137-159.

Grüneberg H (1971a) The tabby syndrome in the mouse. Proc R Soc Lond B Biol Sci 179:139-156.

Grüneberg H (1971b) The glandular aspects of the tabby syndrome in the mouse. J Embryol Exp Morphol 25:1-19.

Hatakeyama C, Anderson CL, Beever CL, Peñaherrera MS, Brown CJ, Robinson WP (2004) The dynamics of X-inactivation skewing as women age. Clin Genet 66:327-332.

Herson PS, Koerner IP, Hurn PD (2009) Sex, sex steroids, and brain injury. Semin Reprod Med 27:229-239.

Hulley S, Grady D, Bush T, Furberg C, Herrington D, Riggs B, Vittinghoff E (1998) Randomized trial of estrogen plus progestin for secondary prevention of coronary heart disease in postmenopausal women. Heart and Estrogen/progestin Replacement Study (HERS) Research Group. JAMA 280:605-613.

Lane PW, Davisson MT (1990) Patchy fur (Paf), a semidominant X-linked gene associated with a high level of $\mathrm{X}-\mathrm{Y}$ nondisjunction in male mice. J Hered 81:43-50.

Lang JT, McCullough LD (2008) Pathways to ischemic neuronal cell death: are sex differences relevant? J Transl Med 6:33.

Li X, Blizzard KK, Zeng Z, DeVries AC, Hurn PD, McCullough LD (2004) Chronic behavioral testing after focal ischemia in the mouse: functional recovery and the effects of gender. Exp Neurol 187:94-104.

Liu F, Yuan R, Benashski SE, McCullough LD (2009) Changes in experimental stroke outcome across the life span. J Cereb Blood Flow Metab 29:792-802.

Lloyd-Jones D, Adams R, Carnethon M, De Simone G, Ferguson TB, Flegal K, Ford E, Furie K, Go A, Greenlund K, Haase N, Hailpern S, Ho M, Howard V, Kissela B, Kittner S, Lackland D, Lisabeth L, Marelli A, McDermott M, et al. (2009) Heart disease and stroke statistics - 2009 update: a report from the American Heart Association Statistics Committee and Stroke Statistics Subcommittee. Circulation 119:480-486.

Lopes AM, Burgoyne PS, Ojarikre A, Bauer J, Sargent CA, Amorim A, Affara NA (2010) Transcriptional changes in response to $\mathrm{X}$ chromosome dosage in the mouse: implications for $\mathrm{X}$ inactivation and the molecular basis of Turner syndrome. BMC Genomics 11:82.

Lue Y, Rao PN, Sinha Hikim AP, Im M, Salameh WA, Yen PH, Wang C, Swerdloff RS (2001) XXY male mice: an experimental model for Klinefelter syndrome. Endocrinology 142:1461-1470.
McCullough LD, Alkayed NJ, Traystman RJ, Williams MJ, Hurn PD (2001) Postischemic estrogen reduces hypoperfusion and secondary ischemia after experimental stroke. Stroke 32:796-802.

McCullough LD, Zeng Z, Blizzard KK, Debchoudhury I, Hurn PD (2005) Ischemic nitric oxide and poly (ADP-ribose) polymerase-1 in cerebral ischemia: male toxicity, female protection. J Cereb Blood Flow Metab 25:502-512.

Migeon BR (2007) Females are mosaics: X inactivation and sex differences in disease. New York: Oxford UP.

Probst FJ, Cooper ML, Cheung SW, Justice MJ (2008) Genotype, phenotype, and karyotype correlation in the $\mathrm{XO}$ mouse model of Turner syndrome. J Hered 99:512-517.

Raefski AS, O’Neill MJ (2005) Identification of a cluster of X-linked imprinted genes in mice. Nat Genet 37:620-624.

Reeves MJ, Bushnell CD, Howard G, Gargano JW, Duncan PW, Lynch G, Khatiwoda A, Lisabeth L (2008) Sex differences in stroke: epidemiology, clinical presentation, medical care, and outcomes. Lancet Neurol 7:915-926.

Renolleau S, Fau S, Goyenvalle C, Joly LM, Chauvier D, Jacotot E, Mariani J, Charriaut-Marlangue C (2007) Specific caspase inhibitor Q-VD-OPh prevents neonatal stroke in P7 rat: a role for gender. J Neurochem 100:1062-1071.

Renolleau S, Fau S, Charriaut-Marlangue C (2008) Gender-related differences in apoptotic pathways after neonatal cerebral ischemia. Neuroscientist 14:46-52.

Schoemaker MJ, Swerdlow AJ, Higgins CD, Wright AF, Jacobs PA (2008) Mortality in women with turner syndrome in Great Britain: a national cohort study. J Clin Endocrinol Metab 93:4735-4742.

Smrt RD, Pfeiffer RL, Zhao X (2011) Age-dependent expression of MeCP2 in a heterozygous mosaic mouse model. Hum Mol Genet 20:1834-1843.

Srivastava AK, Pispa J, Hartung AJ, Du Y, Ezer S, Jenks T, Shimada T, Pekkanen M, Mikkola ML, Ko MS, Thesleff I, Kere J, Schlessinger D (1997) The Tabby phenotype is caused by mutation in a mouse homologue of the EDA gene that reveals novel mouse and human exons and encodes a protein (ectodysplasin-A) with collagenous domains. Proc Natl Acad Sci U S A 94:13069-13074.

Stochholm K, Juul S, Juel K, Naeraa RW, Gravholt CH (2006) Prevalence, incidence, diagnostic delay, and mortality in Turner syndrome. J Clin Endocrinol Metab 91:3897-3902.

Tsuchiya KD, Willard HF (2000) Chromosomal domains and escape from $\mathrm{X}$ inactivation: comparative $\mathrm{X}$ inactivation analysis in mouse and human. Mamm Genome 11:849-854.

Turtzo LC, McCullough LD (2010) Sex-specific responses to stroke. Future Neurol 5:47-59.

Tüttelmann F, Gromoll J (2010) Novel genetic aspects of Klinefelter's syndrome. Mol Hum Reprod 16:386-395.

Viscoli CM, Brass LM, Kernan WN, Sarrel PM, Suissa S, Horwitz RI (2001) A clinical trial of estrogen-replacement therapy after ischemic stroke. N Engl J Med 345:1243-1249.

Wassertheil-Smoller S, Hendrix SL, Limacher M, Heiss G, Kooperberg C, Baird A, Kotchen T, Curb JD, Black H, Rossouw JE, Aragaki A, Safford M, Stein E, Laowattana S, Mysiw WJ (2003) Effect of estrogen plus progestin on stroke in postmenopausal women: the Women's Health Initiative: a randomized trial. JAMA 289:2673-2684. 